\title{
Pengelolaan Limbah Kelapa Sawit (Elaeis guineensis Jacq.) di Perkebunan Kelapa Sawit, Riau
}

\section{Waste Management of Palm Oil (Elaeis guineensis Jacq.) in Oil Palm Plantation, Riau \\ Susilawati dan Supijatno*}

Departemen Agronomi dan Hortikultura, Fakultas Pertanian, Institut Pertanian Bogor (Bogor Agricultural University), Jalan Meranti, Kampus IPB Darmaga, Bogor 16680, Indonesia Telp.\& Faks.62-251-8629353 e-mail agronipb@indo.net.id

*Penulis Korespondensi : supijatno@yahoo.com

Disetujui 7 Mei 2015/ Publish online 15 Mei 2015

\begin{abstract}
The research was conducted at oil palm plantation Riau for three months starting from February $13^{\text {th }} 2012$ to May $13^{\text {th }}$ 2012. The main purpose of this research is to increase knowledge, skill, experience, waste product management of oil palm plantation, and to analyze waste product of palm oil as an organic fertilizer. The analysis results showed that application of empty fruit bunches(EFB) as organic fertilizer has not been able to increase the amount of nutrients on palm oil leaf and increase of palm oil production. Application of palm oil mill effluent (POME) are able to increase the amount of nutrients on palm oil leaf palm oil especially nitrogen and phosphate and a positive impact to increase production of oil palm plantations especially on the productivity (ton/ha).
\end{abstract}

Keywords : By Products, Oil Palm Plantation, Empty Fruit Bunch(EFB), Palm Oil Mill Effluent (POME)

\begin{abstract}
ABSTRAK
Penelitian dilaksanakan di perkebunan kelapa sawit Riau selama tiga bulan yang dimulai pada 13 Februari sampai 13 Mei 2012. Tujuan utama dari penelitian ini adalah untuk meningkatkan pengetahuan, keterampilan, pengalaman, manajemen produk limbah dari perkebunan kelapa sawit, dan untuk menganalisis limbah produk minyak sawit sebagai pupuk organik. Hasil analisis menunjukkan bahwa penerapan tandan kosong sebagai pupuk organik belum mampu meningkatkan jumlah nutrisi pada daun kelapa sawit dan peningkatan produksi minyak sawit. Aplikasi limbah pabrik kelapa sawit yang mampu meningkatkan jumlah nutrisi pada minyak kelapa daun kelapa sawit terutama nitrogen dan fosfat dan dampak positif untuk meningkatkan produksi perkebunan kelapa sawit terutama pada produktivitas (ton / ha).
\end{abstract}

Kata kunci: produk,perkebunan kelapa sawit, tandan kosong (TKS), limbah pabrik kelapa sawit 


\section{PENDAHULUAN}

Kelapa sawit (Elaeis guineensis Jacq.) merupakan komoditas perkebunan yang memegang peranan penting bagi perekonomian Indonesia sebagai salah satu penyumbang devisa non-migas yang cukup besar. Kelapa sawit menghasilkan produk olahan yang mempunyai banyak manfaat (Lubis, 1992). Produk minyak kelapa sawit tersebut digunakan untuk industri penghasil minyak goreng, minyak industri, bahan bakar, industri kosmetik dan farmasi.

Luas perkebunan kelapa sawit di Indonesia pada tahun 2005 yaitu seluas 4520600 ha dan terjadi peningkatan yang cukup besar pada tahun 2010 yaitu menjadi 8430027 ha (Badan Pusat Statistik, 2011). Luas perkebunan kelapa sawit yang besar akan diiringi dengan volume ekspor yang tinggi pula, hal tersebut dikarenakan permintaan dunia akan minyak sawit terus meningkat sehingga pasaran ekspornya selalu terbuka lebar dan dapat menghasilkan keuntungan yang besar. Volume ekspor CPO pada tahun 2006 sebesar 11745954 ton mencapai nilai US\$ 4139 286000 dan pada tahun 2009 meningkat menjadi 20615958 ton atau senilai US\$12626595000 (Direktorat Jenderal Perkebunan, 2011).

Pertambahan dan peningkatan areal pertanaman kelapa sawit diiringi pertambahan jumlah industri pengolahannya menyebabkan jumlah limbah yang dihasilkan semakin banyak pula. Hal tersebut disebabkan oleh bobot limbah pabrik kelapa sawit (PKS) yang harus dibuang semakin bertambah. Limbah yang dihasilkan dari proses pengolahan kelapa sawit akan menimbulkan dampak negatif bagi lingkungan, baik kuantitas sumber daya alam, kualitas sumber daya alam, maupun lingkungan hidup.

Dampak negatif limbah yang dihasilkan dari suatu industri menuntut pabrik agar dapat mengolah limbah dengan cara terpadu. Pemanfaatan limbah menjadi bahan-bahan yang menguntungkan atau mempunyai nilai ekonomi tinggi dilakukan untuk mengurangi dampak negatif bagi lingkungan dan mewujudkan industri yang berwawasan lingkungan.

Limbah industri pertanian khususnya industri kelapa sawit mempunyai ciri khas berupa kandungan bahan organik yang tinggi. Kandungan bahan organik tersebut dapat dimanfaatkan untuk pertumbuhan kelapa sawit. Limbah PKS memungkinkan dimanfaatkan pada lahan perkebunan kelapa sawit untuk menghindari pencemaran lingkungan dan mengatasi kebutuhan pupuk.

diperdalam (aspek khusus) pada kegiatan magang ini adalah pengelolaan limbah hasil 204
Limbah padat yang dihasilkan pabrik kelapa sawit berupa janjang kosong (JJK) yang jumlahnya sekitar $20 \%$ dari TBS yang diolah dan merupakan bahan organik yang kaya akan unsur hara (Direktorat Pengolahan Hasil Pertanian, 2006). Aplikasi JJK berpotensi tinggi sebagai bahan pembenah tanah, memperbaiki sifat fisik dan kimia tanah, serta meningkatkan produksi kelapa sawit (Darmosarkoro et al., 2003).

Limbah cair pabrik kelapa sawit (LCPKS) yang dikenal dengan istilah POME (Palm Oil Mill Effluent) mempunyai kandungan bahan organik yang tinggi, sehingga LCPKS harus diolah atau dimanfaatkan untuk pupuk. Limbah cair pabrik kelapa sawit memilki sejumlah kandungan hara yang dibutuhkan tanaman, yaitu N, P, K, Ca dan $\mathrm{Mg}$ yang berpotensi sebagai sumber hara untuk tanaman (Budianta, 2005)

Kegiatan magang ini mempunyai tujuan umum untuk menambah pengalaman, meningkatkan kemampuan teknis dan manajerial perkebunan kelapa sawit, serta meningkatkan kemampuan mahasiswa dalam memahami proses kerja secara nyata. Tujuan khusus dalam kegiatan magang ini untuk mempelajari pengelolaan dan pemanfaatan limbah kelapa sawit sebagai pupuk organik yang berhubungan dengan aspek budidaya tanaman serta mengetahui dampak aplikasinya terhadap tanaman dan dampak aplikasi limbah cair terhadap kualitas air.

\section{BAHAN DAN METODE}

Kegiatan penelitian dilaksanakan Perkebunan kelapa sawit di Riau mulai dari tanggal 13 Februari sampai 13 Mei 2012.

Kegiatan penelitian yang dilakukan meliputi seluruh kegiatan aspek teknis di lapangan dan aspek manajerial baik di kebun maupun di kantor, melakukan pengamatan terhadap aspek khusus di lapangan serta kegiatan pengumpulan data. Kegiatan-kegiatan tersebut disesuaikan dengan jadwal dan kebutuhan di kebun serta disetujui oleh pihak kebun. Kegiatan yang dilaksanakan penulis pada aspek teknis yaitu penulis diposisikan sebagai karyawan harian lepas (KHL) selama tiga minggu yang bekerja di lapangan sesuai dengan jenis pekerjaan yang ada. Pada aspek manajerial penulis mengikuti kegiatan sebagai pendamping supervisi (mandor dan kerani) selama tiga minggu dan pendamping asisten selama enam minggu. Selain mengikuti aspek teknis dan manajerial, aspek yag pengolahan kelapa sawit yang dilakukan oleh perusahaan. 
Pengamatan dan Pengumpulan Data dan Informasi

Pengumpulan data dilakukan dengan metode langsung (primer) dan tidak langsung (sekunder). Pengamatan data primer dilakukan langsung pada saat mengikuti kegiatan di lapangan sesuai dengan aspek teknis dan aspek khusus yang dipelajari serta diskusi dan wawancara dengan mandor, pegawai dan asisten kebun, sedangkan data sekunder diperoleh dari data kantor kebun.

\section{Pengamatan limbah padat kelapa sawit (Janjang} Kosong)

1. Jumlah dan distribusi limbah janjang kosong di lahan

2. Dosis dan cara aplikasi janjang kosong di lahan

3. Jumlah tenaga kerja yang mengaplikasikan janjang kosong di lahan

\section{Pengamatan limbah cair kelapa sawit}

1. Jumlah limbah cair yang dihasilkan pabrik

2. Jumlah dan kapasitas kolam-kolam penampungan limbah cair

3. Jumlah dan distribusi limbah cair yang diaplikasikan di lahan

4. Dosis dan cara aplikasi limbah cair di lahan

5. Jumlah tenaga kerja yang mengaplikasikan limbah cair di lahan

Data sekunder yang dikumpulkan meliputi:

1. Kondisi umum kebun meliputi sejarah dan perkembangan, letak goegrafis kebun, keadaan iklim dan tanah, luas areal dan tata guna lahan., kondisi pertanaman dan produktivitas tanaman lima tahun terakhir, struktur organisasi dan ketenagakerjaan kebun.

2. Data produksi limbah padat dan limbah cair yang dihasilkan pabrik kelapa sawit selama 16 bulan terakhir.

3. Data perolehan produksi (ton/ha), bobot janjang rata-rata $(\mathrm{kg})$, dan jumlah janjang (janjang/ha) selama empat tahun terakhir untuk blok aplikasi limbah dan blok yang tidak diaplikasikan limbah.

4. Data hasil analisa status hara dalam daun tanaman kelapa sawit pada blok aplikasi limbah dan blok yang tidak diaplikasikan limbah.

5. Kualitas air limbah cair (BOD, COD, kandungan minyak dan lemak, TSS, $\mathrm{pH}$, amoniak, timbal, tembaga, kadmium, dan seng).

6. Kulitas air sumur pantau yang ada di sekitar lahan aplikasi dan kualitas air sungai hulu dan hilir sungai yang ada di dekat pabrik.

Data hasil analisis status hara dalam daun kelapa sawit dan perolehan produksi tanaman kelapa sawit antara blok yang diaplikasikan limbah dan blok yang tidak diaplikasikan limbah diuji dengan menggunakan uji hipotesis $t$-student. Jumlah blok untuk variabel yang diuji dibandingkan masing-masing sebanyak tiga blok sebagai ulangan, dan variabel pengamatan lainnya dianalisis secara deskriptif. Rumus $t$-student. Data dan informasi lainnya akan dianalisis dengan penggunaan rata-rata, persentase, dan dianalisis secara deskriptif.

Perkebunan terletak di Desa Tualang Perawang, Kecamatan Tualang, Kabupaten Siak, Provinsi Riau. Keadaan iklim di perkebunan berdasarkan periode 2007 - 2011 curah hujan tahunan terendah yaitu $2048 \mathrm{~mm}$ dan tertinggi 2 $743 \mathrm{~mm}$, rata-rata curah hujan tahunan sebesar 2 $420.4 \mathrm{~mm} /$ tahun. Total hari hujan selama periode 2007 - 2011 berkisar antara 143 - 168 hari/tahun dan rata-ratanya 153.8 hari/tahun. Suhu rata-rata harian yaitu $20-35{ }^{0} \mathrm{C}$ dan lama penyinaran matahari perhari di kebun maksimal 12 jam.

Areal pekebunan kelapa sawit memiliki luas total berdasarkan Hak Guna Usaha (HGU) sebesar 3321.20 ha dengan luas lahan yang diusahakan yaitu sebesar 3116.98 ha dan luas lahan yang mungkin bisa ditanam sebesar 204.22 ha.

Varietas kelapa sawit yang ditanam di perkebunan kelapa sawit adalah jenis tenera dengan varietas Socfindo, Marihat, Guthrie, Lonsum, dan Rispa dan terdiri dari 12 tahun tanam. Jarak tanam yang digunakan adalah 9.2 $\mathrm{m} \times 9.2 \mathrm{~m}$ x $9.2 \mathrm{~m}$ dengan jarak antar barisan $7.96 \mathrm{~m}$ dan jarak dalam barisan $9.2 \mathrm{~m}$ sehingga populasi per hektarnya 136 pokok. Produksi dan produktivitas kebun dapat dilihat pada Tabel 1. Indeks tenaga kerja di teluk Siak Estate sebesar 0.16 , sedangkan standar ITK untuk perkebunan kelapa sawit adalah $0.2-0.4$ (Pahan, 2010). 
Tabel 1. Produksi dan Produktivitas Kebun Lima Tahun Terakhir

\begin{tabular}{cccc}
\hline Tahun & $\begin{array}{c}\text { Luas Areal } \\
\text { (ha) }\end{array}$ & Produksi (ton) & $\begin{array}{c}\text { Produktivitas } \\
\text { (ton/ha) }\end{array}$ \\
\hline $2006 / 2007$ & 2698 & 47774280 & 17.71 \\
$2007 / 2008$ & 2725 & 53120400 & 19.49 \\
$2008 / 2009$ & 2725 & 48977990 & 17.97 \\
$2009 / 2010$ & 2725 & 47210270 & 17.32 \\
$2010 / 2011$ & 2822 & 53577460 & 18.98 \\
\hline
\end{tabular}

Sumber: Kantor Besar TSE (2012)

\section{HASIL DAN PEMBAHASAN}

\section{Produksi, Karakteristik Pengelolaan Limbah Kelapa Sawit}

Pengolahan tandan buah segar (TBS) yang dilakukan pabrik pengolahan kelapa sawit menghasilkan produk sampingan (by product) dalam bentuk limbah padat yang berupa serabut, janjang kosong (JJK), dan cangkang serta limbah cair yang biasanya dikenal dengan POME (Palm Oil Mill Effluent). PT Aneka Intipersada memiliki satu pabrik kelapa sawit yaitu Teluk Siak Factory (TSF) yang memiliki kapasitas olah 45 ton/jam. Jumlah limbah padat dan cair yang dihasilkan pabrik selama bulan Januari 2011 April 2012 yaitu JJK sekitar $18.85 \%$ dari TBS yang diolah, fiber sekitar $13 \%$ dari TBS yang diolah, cangkang sekitar $5 \%$ dari TBS yang diolah, dan POME sekitar $60.09 \%$ dari TBS yang diolah. Berdasarkan pengamatan selama bulan April 2012 rata-rata TBS yang diolah TSF yaitu 564.780 ton/hari dan menghasilkan janjang kosong sebanyak 116.922 ton/hari atau sekitar $20.7 \%$ dari TBS diolah, fiber sebanyak 73.421 ton/hari atau sekitar $11.04 \%$ dari TBS diolah, cangkang sebesar 28.239 ton/hari atau sekitar 5 $\%$ dari TBS diolah, dan POME sebanyak 355.059 ton/hari atau sekitar $62.87 \%$ dari TBS yang diolah.

Limbah padat cangkang dan fiber digunakan untuk bahan bakar boiler dalam pengolahan TBS di PKS, sedangkan JJK dan POME diaplikasikan sebagai pupuk organik ke lapangan dengan cara aplikasi yang tepat dan dosis yang tepat sesuai rekomendasi dari Departemen Riset.

\section{Aplikasi Janjang Kosong (JJK)}

Janjang kosong (JJK) merupakan salah satu produk sampingan dari hasil pengolahan TBS dan berasal dari stasiun bantingan (thresher) di PKS. JJK yang dihasilkan oleh Teluk Siak Factory (TSF) sebesar $16-21 \%$ dari jumlah TBS yang diolah atau sebesar $160-210 \mathrm{~kg} / \mathrm{ton}$ dari TBS yang diolah. JJK yang dihasilkan pabrik di tampung di hopper kemudian langsung diangkut ke lahan menggunakan truk DT Colt Diesel dengan kapasitas angkut 6 ton dan jenis truk DT Colt Diesel HINO kapasitas angkut yaitu 8 ton, truk tersebut mengangkut JJK setelah mengantarkan TBS ke PKS. JJK yang diangkut kemudian diletakkan (ditumpuk) di pinggir collection road.

Metode aplikasi JJK di TSE dengan teknik mulching yang diaplikasikan diantara empat pokok untuk satu titik pada tanaman menghasilkan (TM). JJK diaplikasikan di gawangan mati dengan dosis $250 \mathrm{~kg} /$ pokok sehingga dalam satu titik ada 1 ton JJK dan dibutuhkan JJK sebanyak 34 ton/ha dengan rotasi satu kali setahun. Jumlah JJK yang masuk ke TSE rata-rata setiap bulan yaitu sebanyak 1472.285 ton dan TSE menerima JJK sebanyak 17667.42 ton/tahun sehingga luasan yang dapat diaplikasi seluas $519.63 \mathrm{ha} /$ tahun atau sekitar $17.75 \%$ dari luas total TSE (dosis 34 ton/ha dengan satu kali rotasi setahun). Berdasarkan data yang diperoleh luas lahan aplikasi JJK di TSE pada tahun 2011/2012 yaitu 461.3 ha (sekitar $15.82 \%$ dari luas total TSE) dan lebih kecil dibandingkan luasan yang seharusnya dapat diaplikasi. Hal tersebut dikarenakan dosis aplikasi yang tidak sesuai dan melebihi dosis aplikasi yang ditentukan yaitu 34 ton/ha/tahun.

Organisasi pekerjaan aplikasi JJK di TSE dilakukan oleh karyawan SKU, di divisi II TSE untuk satu hari aplikasi JJK empat orang karyawan yang bekerja untuk aplikasi JJK yang diwasi oleh satu orang mandor. Prestasi kerja yang ditetapkan di lapangan yaitu 7 ton/ $\mathrm{HK}$ atau 28 ton/hari sehingga dalam satu hari memperoleh 28 titik aplikasi atau seluas 0.824 ha, untuk menyelesaikan luasan 1 ha diperlukan prestasi kerja 5 $\mathrm{HK} /$ ha/rotasi (dosis aplikasi 34 ton JJK/ha atau 250 $\mathrm{kg}$ /pokok). Apabila aplikasi JJK dilakukan oleh buruh harian lepas (BHL) maka upah dihitung berdasarkan jumlah JJK yang dapat diaplikasikan yaitu Rp 3 000.00/ton, sehingga biaya aplikasi per HK untuk satu kali rotasi sebesar Rp 102000.00 (dosis 34 ton JJK/HK).

Tenaga kerja aplikasi JJK yang ada di TSE seperti di Divisi II belum bekerja secara khusus bekerja mengaplikasikan JJK. Tenaga kerja 
tersebut dapat mengerjakan pekerjaan lain yang lebih diutamakan sehingga aplikasi JJK tidak dapat menyebabkan JJK terlalu lama menumpuk di collection road karena tidak dapat langsung diaplikasikan ke lahan sehingga unsur hara yang terkandung pada JJK akan berkurang.

\section{Aplikasi Limbah Cair (POME)}

Limbah cair (POME) merupakan produk sampingan (by product) yang dihasilkan dari pengolahan TBS di PKS dan berasal dari proses dilakukan setiap hari. Kurangnya tenaga kerja aplikasi dan belum adanya tenaga kerja khusus perebusan (sterilizer), pemurnian (clarifier), air cucian pabrik, dan air hydrocyclon (air pemisahan proses pemisahan cangkang dan inti sawit). Parameter pencemaran limbah cair yang digunakan yaitu pH, BOD, COD, TS, minyak dan lemak, Ntotal, serta logam berat. Baku mutu limbah cair yang diambil dari kolam raw effluent dan effluent treatment di Teluk Siak Factory (TSF) pada pemeriksaan bulan Desember 2011 dapat dilihat pada Tabel 2.

Tabel 2. Hasil Pemerikasaan Kualitas Air Limbah dari Raw Effluent dan Effluent Treatment PT AIP

\begin{tabular}{|c|c|c|c|c|c|}
\hline \multirow[b]{2}{*}{ Parameter } & \multirow[b]{2}{*}{ Satuan } & \multirow{2}{*}{$\begin{array}{l}\text { PERGUB NO. } 35 \\
\text { Tahun 2007(Kadar } \\
\text { Maks) }\end{array}$} & \multirow{2}{*}{$\begin{array}{c}\text { KEPMENLH NO. } 28 \\
\text { Tahun } 2003 \text { (Kadar } \\
\text { Maks) }\end{array}$} & \multicolumn{2}{|c|}{ Hasil } \\
\hline & & & & LC Raw Effluent & $\begin{array}{c}\text { LC Effluent } \\
\text { Treatment }\end{array}$ \\
\hline $\mathrm{pH}$ & - & $6-9$ & $6-9$ & 4.38 & 7.65 \\
\hline $\mathrm{BOD}_{5}$ & $\mathrm{mg} / \mathrm{L}$ & 5000 & 5000 & 14120.6 & 626.7 \\
\hline COD & $\mathrm{mg} / \mathrm{L}$ & 10000 & $*$ & 46428.5 & 1438.1 \\
\hline Minyak dan Lemak & $\mathrm{mg} / \mathrm{L}$ & 2500 & $*$ & 1 & 1 \\
\hline TSS & $\mathrm{mg} / \mathrm{L}$ & 12500 & $*$ & 10400.0 & 1600.0 \\
\hline Amoniak $\left(\mathrm{NH}_{3}-\mathrm{N}\right)$ & $\mathrm{mg} / \mathrm{L}$ & 500 & $*$ & 75.47 & 137.2 \\
\hline Timbal (Pb) & $\mathrm{mg} / \mathrm{L}$ & $*$ & $*$ & $<0.015$ & $<0.015$ \\
\hline Tembaga $(\mathrm{Cu})$ & $\mathrm{mg} / \mathrm{L}$ & $*$ & $*$ & 0.547 & 0.026 \\
\hline $\operatorname{Kadmium}(\mathrm{Cd})$ & $\mathrm{mg} / \mathrm{L}$ & $*$ & $*$ & $<0.008$ & $<0.008$ \\
\hline
\end{tabular}

Hasil analisis pada kolam LC effluent treatment yang telah mengalami proses pengolahan limbah menunjukkan bahwa semua parameter memenuhi baku mutu yang ditetapkan sehingga aman untuk diaplikasikan ke lahan.

Sistem pengolahan limbah di TSF menggunakan sistem kolam dengan tujuan dapat menurunkan kadar cemarnya terutama nilai BOD dan COD limbah agar dapat diaplikasikan ke lahan. Limbah cair yang dihasilkan pabrik akan ditampung pada sistem IPAL yang terdiri dari 8 kolam. Spesifikasi kolam limbah di IPAL TSF dapat dilihat pada Tabel 3.

Tabel 3. Spesifikasi Kolam Limbah di IPAL TSF

\begin{tabular}{llccc}
\hline \multicolumn{1}{c}{ Kolam } & Ukuran $(\mathrm{pxlxt})(\mathrm{m})$ & Volume $\left(\mathrm{m}^{3}\right)$ & $\begin{array}{c}\text { Masa Retensi } \\
(\text { hari })\end{array}$ \\
\hline 1 & Deoiling Pond & $34 \times 18 \times 4$ & 2448 & $2-4$ \\
2 & Cooling Pond & $29 \times 15 \times 4$ & 1740 & $4-6$ \\
3 & Primary Pond No. 1 & $58 \times 24 \times 4.5$ & 7308 & $10-24$ \\
4 & Primary Pond No. 2 & $58 \times 24 \times 4.5$ & 7308 & $10-24$ \\
5 & Secondary Pond No. 1 & $58 \times 24 \times 4.5$ & 7308 & $14-24$ \\
6 & Secondary Pond No. 2 & $58 \times 24 \times 4.5$ & 7308 & $14-24$ \\
7 & Sedimentasi Pond No. 1 & $58 \times 24 \times 4.5$ & 7308 & $13-24$ \\
8 & Sedimentasi Pond No. 2 & $58 \times 24 \times 4.5$ & 7308 & $13-24$ \\
\hline
\end{tabular}

Sumber: Teluk Siak Factory (2012)

Limbah cair yang telah diolah diaplikasikan di lahan dengan menggunakan sistem flat bed (kolam datar). Flat bed dibuat di gawangan mati yaitu gawangan yang berselingan dengan pasar rintis/jalan panen, berbentuk empat pesegi panjang dengan ukuran panjang $3 \mathrm{~m}$, lebar $2.1 \mathrm{~m}$, dan kedalaman $0.6 \mathrm{~m}$ sehingga volume flat bed yaitu $3.84 \mathrm{~m}^{3}$. Jarak antar flat bed dipisahkan pematang dengan lebar $0.4-0.5 \mathrm{~m}$.

Blok aplikasi limbah cair PT AIP terletak di Divisi II TSE yang letaknya paling 
dekat dengan pabrik. Luas lahan aplikasi limbah cair saat ini seluas 120 ha, jumlah flat bed 15694 buah dengan total volume flat bed yaitu 16 jam/hari dan debit limbah yang diaplikasikan $46 \mathrm{~m}^{3} / \mathrm{jam}$ sehingga banyaknya limbah cair yang diaplikasikan yaitu $736 \mathrm{~m}^{3} /$ hari atau $18400 \mathrm{~m}^{3} /$ bulan (18 381.6 ton/bulan). Luas total lahan yang diaplikasikan limbah cair yaitu 120 ha sehingga dosis aplikasi yang diperoleh yaitu $\quad 153.333 \quad \mathrm{~m}^{3} / \mathrm{ha} /$ bulan $\quad(153.180$ ton/ha/bulan) atau sekitar $1839.996 \mathrm{~m}^{3} / \mathrm{ha} /$ tahun (1 838.156 ton/ha/tahun). Aplikasi limbah cair dilakukan setiap hari dengan rotasi aplikasi setiap blok mendapatkan empat kali aplikasi dalam satu bulan.

Tenaga kerja aplikasi limbah cair terdiri dari tiga orang pekerja yang terbagi dalam dua shift, satu orang bekerja pagi hari sampai sore dan dua orang bekerja dari sore sampai malam atau sampai pagi esok hari. Tenaga kerja di

pabrik terdiri dari dua orang karyawan yang terbagi dari dua shift, satu orang bekerja dari pagi sampai sore dan satu lainnya dari sore sampai malam atau esok hari yang biaya tenaga kerja dibebankan ke pihak PKS. Standar kerja yang ditetapkan untuk aplikasi limbah cair yaitu 7 jam/HK dan aplikasi di luar jam kerja untuk pekerja pabrik dan pekerja kebun dihitung sebagai lembur. Prestasi kerja yang diperoleh karyawan pabrik dan karyawan kebun rata-rata di atas standar yang sudah ditetapkan.

\section{Dampak Aplikasi Limbah terhadap Tanaman}

Analisis dampak aplikasi limbah terhadap tanaman dilakukan dengan membandingkan kandungan unsur hara daun dan perolehan produksi antara lahan yang diaplikasikan limbah dengan lahan yang tidak diaplikasikan limbah (lahan kontrol). Blok yang digunakan untuk perbandingan aplikasi limbah padat (JJK) yaitu Blok E19, E20, E21 dengan blok kontrolnya Blok F15, F16, F17 yang masing-masing tahun tanamnya tahun 1996, sedangkan blok yang digunakan untuk aplikasi limbah cair (POME) yaitu Blok F27, F28, G29 dengan blok kontrolnya yaitu Blok E20, E21, E22 yang masing-masing tahun tanamnya tahun 1994. Parameter unsur hara yang dibandingkan adalah kandungan unsur $\mathrm{N}, \mathrm{P}, \mathrm{K}$, dan yang masingmasing dinyatakan dalam $\%$ on dry matter serta parameter produksi yang dibandingkan yaitu produktivitas tanaman (ton/ha), jumlah janjang (janjang/ha), dan bobot janjang rata-rata $(\mathrm{kg})$.

\section{Dampak Aplikasi Limbah terhadap Status Hara pada Daun}

$60265 \mathrm{~m}^{3}$ dan jumlah kran 499 buah. Rata-rata aplikasi limbah cair untuk pengisian flat bed

Dampak aplikasi limbah terhadap status hara daun dilihat dengan menaganalisis kandungan status hara daun dengan membandingkan hasil analisa daun antara lahan yang diaplikasikan limbah dan lahan yang tidak diaplikasikan limbah (lahan kontrol). Lahan yang akan dibandingkan masing-masing diambil 3 (tiga) blok sebagai ulangan dan parameter yang dibandingkan yaitu unsur $\mathrm{N}, \mathrm{P}, \mathrm{K}$, dan $\mathrm{Mg}$ yang masing-masing dinyatakan dalam $\%$ on $d r y$ matter. Hasil analisa kandungan unsur hara daun pada lahan aplikasi dan lahan kontrol JJK dan limbah cair (POME) disajikan pada Tabel 4 dan Tabel 5 .

Tabel 4. Hasil Analisa Daun pada Lahan Aplikasi JJK dan Lahan Kontrol

\begin{tabular}{ccc}
\hline $\begin{array}{c}\text { Kandungan Hara dalam } \\
\text { Daun (\% On Dry } \\
\text { Matter) }\end{array}$ & $\begin{array}{c}\text { Lahan } \\
\text { Aplikasi }\end{array}$ & $\begin{array}{c}\text { Lahan } \\
\text { Kontrol }\end{array}$ \\
\hline $\mathrm{N}$ & $2.5300 \mathrm{a}$ & $2.6800 \mathrm{a}$ \\
$\mathrm{P}$ & $0.1373 \mathrm{a}$ & $0.1317 \mathrm{a}$ \\
$\mathrm{K}$ & $1.1847 \mathrm{a}$ & $1.1897 \mathrm{a}$ \\
& $0.2187 \mathrm{a}$ & $0.1933 \mathrm{a}$ \\
\hline $\begin{array}{l}\text { Sumber } \\
\text { Keterangan : Angka pada baris yang sama dan diikuti huruf } \\
\text { yang sama menunjukkan hasil yang tidak berbeda } \\
\text { nyata berdasarkan uji t-student pada taraf nyata 5 } \\
\text { \%. }\end{array}$
\end{tabular}

Dari hasil analisa sampel daun tanaman kelapa sawit dapat dilihat bahwa kandungan hara daun antara lahan aplikasi JJK dan lahan kontrol menunjukkan hasil yang tidak berbeda nyata. Hal tersebut diakibatkan karena aplikasi JJK belum dilakukan secara maksimal (full block) dan tidak merata, artinya dari total luasan satu blok hanya sebagian saja yang teraplikasi JJK. Sebagai contoh yaitu pada Blok E19 yang mempunyai total luas blok 22 ha, pada tahun 2005/2006 baru 13.15 ha saja yang diaplikasi JJK. Aplikasi JJK hanya dilakukan pada pokok yang berada di dekat tumpukan JJK saja tidak sampai masuk ke dalam blok karena kontur lahan yang tidak rata (bergelombang) dan sarana blok seperti titi panen dan pasar rintis yang kurang memadai sehingga menyulitkan aplikasi JJK secara manual. Kandungan unsur hara N, K dan Mg pada lahan aplikasi JJK serta unsur hara $\mathrm{N}$ dan $\mathrm{K}$ pada lahan 
kontrol berada pada kondisi optimum. Unsur hara $\mathrm{P}$ pada lahan aplikasi dan unsur hara $\mathrm{P}$ dan $\mathrm{Mg}$ pada lahan kontrol berada pada kondisi defisiensi (kekurangan). Aplikasi JJK di lahan dapat meningkatkan kandungan unsur hara $\mathrm{Mg}$ yang berada pada kondisi defisiensi pada lahan kontrol menjadi optimum pada lahan aplikasi, tetapi belum dapat meningkatkan kandungan unsur hara $\mathrm{P}$.

Tabel 5. Hasil Analisa Daun pada Lahan Aplikasi Limbah Cair (LA) dan Lahan Kontrol (LK)

\begin{tabular}{ccc}
\hline $\begin{array}{c}\text { Kandungan Hara dalam } \\
\text { Daun (\% On Dry Matter) }\end{array}$ & $\begin{array}{c}\text { Lahan } \\
\text { Aplikasi (LA) }\end{array}$ & $\begin{array}{c}\text { Lahan } \\
\text { Kontrol (LK) }\end{array}$ \\
\hline $\mathrm{N}$ & $2.9033 \mathrm{a}$ & $2.4700 \mathrm{~b}$ \\
$\mathrm{P}$ & $0.1623 \mathrm{a}$ & $0.1333 \mathrm{~b}$ \\
$\mathrm{~K}$ & $1.0837 \mathrm{a}$ & $1.1947 \mathrm{a}$ \\
$\mathrm{Mg}$ & $0.2260 \mathrm{a}$ & $0.2070 \mathrm{a}$
\end{tabular}

Sumber: Minamas Research Centre (2009)

Keterangan : Angka pada baris yang sama dan diikuti huruf yang sama menunjukkan hasil yang tidak berbeda nyata berdasarkan uji t-student pada taraf nyata 5 $\%$.

Hasil analisa sampel daun tanaman kelapa sawit pada blok aplikasi limbah cair dan blok control (Tabel 5) menyatakan bahwa hanya kandungan unsur $\mathrm{N}$ dan $\mathrm{P}$ saja yang berbeda nyata meskipun perbedaannya tidak terlalu tinggi, sedangkan kandungan unsur $\mathrm{K}$ dan $\mathrm{Mg}$ tidak berbeda nyata. Menurut hasil penelitian yang dilakukan oleh Budianta (2005), limbah cair yang dihasilkan dan siap diaplikasikan ke lahan perkebunan mempunyai kandungan K 500 - 600 mg/l, N 142 - 157 mg/l, P 24-53 mg/l, dan Mg 39 $90 \mathrm{mg} / \mathrm{l}$. Berdasarkan analisis tersebut perbedaan kandungan unsur hara tidak terlalu tinggi dikarenakan limbah yang diaplikasikan nilai BOD nya yang tidak terlalu tinggi $(<2500 \mathrm{mg} / \mathrm{l})$.

Unsur hara $\mathrm{P}$ pada lahan aplikasi dan unsur hara $\mathrm{P}$ dan $\mathrm{Mg}$ Kandungan unsur hara N, P, K dan $\mathrm{Mg}$ pada lahan aplikasi limbah cair serta unsur hara $\mathrm{N}, \mathrm{K}$ dan $\mathrm{Mg}$ pada lahan kontrol berada pada kondisi optimum. Aplikasi limbah cair dapat meningkatkan kandungan unsur hara $\mathrm{P}$, hal tersebut dilihat dari kandungan unsur hara $\mathrm{P}$ di lahan kontrol berada pada kondisi defisiensi sedangkan di lahan aplikasi berada pada kondisi optimum.

\section{Dampak Aplikasi Limbah terhadap Perolehan Produksi}

Analisis terhadap dampak aplikasi limbah terhadap perolehan produksi dilakukan dengan membandingkan perolehan produksi lahan yang diaplikasikan limbah dengan lahan yang tidak diaplikasikan limbah. Tabel perbadingan produksi antara lahan aplikasi dan lahan kontrol JJK dan limbah cair dapat dilihat pada Tabel 6 dan Tabel 7.

Tabel 6. Perbandingan Produksi antara Lahan Aplikasi JJK dan Lahan Kontrol

\begin{tabular}{cccc}
\hline Parameter & Tahun & Lahan Aplikasi & $\begin{array}{c}\text { Lahan } \\
\text { Kontrol }\end{array}$ \\
\hline & $2006 / 2007$ & $17.58 \mathrm{a}$ & $17.65 \mathrm{a}$ \\
Produktivitas & $2007 / 2008$ & $18.80 \mathrm{a}$ & $17.61 \mathrm{a}$ \\
(ton/ha) & $2008 / 2009$ & $16.00 \mathrm{a}$ & $13.65 \mathrm{a}$ \\
& $2009 / 2010$ & $15.29 \mathrm{a}$ & $14.07 \mathrm{a}$ \\
\hline & $2006 / 2007$ & $1502 \mathrm{a}$ & $1588 \mathrm{a}$ \\
\hline Jumlah Janjang 2007/2008 & $1489 \mathrm{a}$ & $1375 \mathrm{~b}$ \\
(JJG/ha) & $2008 / 2009$ & $1182 \mathrm{a}$ & $1061 \mathrm{a}$ \\
& $2009 / 2010$ & $1040 \mathrm{a}$ & $973 \mathrm{a}$ \\
\hline Bobot Janjang $2007 / 2008$ & $12.63 \mathrm{a}$ & $12.81 \mathrm{a}$ \\
\hline Rata-rata (kg) & $2008 / 2009$ & $13.53 \mathrm{a}$ & $12.86 \mathrm{~b}$ \\
& $2009 / 2010$ & $14.70 \mathrm{a}$ & $14.43 \mathrm{a}$ \\
\hline Sumber: Kantor Besar TSE (2012) & &
\end{tabular}

Sumber: Kantor Besar TSE (2012)

Keterangan: Angka pada baris yang sama dan diikuti huruf yang sama menunjukkan hasil yang tidak berbeda nyata berdasarkan uji t-student pada taraf nyata $5 \%$.

Berdasarkan hasil analisis terhadap perolehan produksi (Tabel 6), aplikasi JJK belum memberikan pengaruh yang berbeda nyata untuk produktivitas dan jumlah janjang antara lahan aplikasi dan lahan kontrol. Pada tahun 2006/2007 dan 2008/2009 perolehan BJR menunjukkan hasil yang berbeda nyata, tetapi secara keseluruhan aplikasi JJK belum dapat meningkatkan perolehan produksi secara konsisten. Hal tersebut dikarenakan aplikasi JJK belum diaplikasikan secara maksimal dan tidak merata sepanjang tahun serta JJK terlalu lama ditumpuk di collection road. Sebagai contoh pada Blok E20 yang mempunyai luasan total 17 ha, pada tahun 2007/2008 luas lahan yang diaplikasi JJK hanya 5.32 ha dan tahun 2007/2008 pada blok yang sama tidak dilakukan aplikasi JJK. 
Aplikasi limbah cair ke lahan memberikan dampak positif bagi perolehan produksi tanaman kelapa sawit terutama terhadap produktivitas (ton/ha). Tahun 2006-2007 dan 2007-2008 produktivitas lahan aplikasi berbeda nyata lebih tinggi dibandingkan lahan kontrol (Tabel 7).

Tabel 7. Perbandingan Produksi antara Lahan Aplikasi Limbah Cair (LA) dan Lahan Kontrol (LK)

\begin{tabular}{cccc}
\hline \multirow{2}{*}{ Parameter } & Tahun & Lahan Aplikasi & Lahan \\
& $2006 / 2007$ & $24.31 \mathrm{a}$ & $20.75 \mathrm{~b}$ \\
\hline & & Kontrol (LK) \\
Produktivitas & $2007 / 2008$ & $27.02 \mathrm{a}$ & $22.37 \mathrm{~b}$ \\
(ton/ha) & $2008 / 2009$ & $24.08 \mathrm{a}$ & $22.35 \mathrm{a}$ \\
& $2009 / 2010$ & $22.81 \mathrm{a}$ & $20.14 \mathrm{a}$ \\
\hline \multirow{2}{*}{ Jumlah } & $2006 / 2007$ & $1432 \mathrm{a}$ & $1275 \mathrm{a}$ \\
(janjang/ha) & $2008 / 2009$ & $1278 \mathrm{a}$ & $1238 \mathrm{a}$ \\
& $2009 / 2010$ & $1207 \mathrm{a}$ & $1082 \mathrm{a}$ \\
\hline & $2006 / 2007$ & $16.98 \mathrm{a}$ & $16.19 \mathrm{a}$ \\
\hline Bobot Janjang & $2007 / 2008$ & $18.22 \mathrm{a}$ & $18.23 \mathrm{a}$ \\
Rata-rata (kg) & $2008 / 2009$ & $18.51 \mathrm{a}$ & $18.05 \mathrm{~b}$ \\
& $2009 / 2010$ & $18.90 \mathrm{a}$ & $18.60 \mathrm{a}$ \\
\hline
\end{tabular}

Sumber: Kantor Besar TSE (2012)

Keterangan: Angka pada baris yang sama dan diikuti huruf yang sama menunjukkan hasil yang tidak berbeda nyata berdasarkan uji t-student pada taraf nyata $5 \%$.

Lebih tingginya produktivitas tanaman dari lahan aplikasi limbah cair dikarenakan aplikasi limbah cair ke lahan dapat menambah ketersediaan air di lapangan dan sebagai irigasi pada bulan-bulan kering. Limbah cair yang diaplikasikan ke lahan masih mengandung unsur hara yang dibutuhkan tanaman yang dapat dijadikan sebagai sumber tambahan hara bagi tanaman.

Kekeringan berdampak signifikan terhadap tanaman kelapa sawit dan berpengaruh terhadap nisbah bunga jantan dan bunga betina. Menurut Darmosarkoro et al. (2005) tanaman yang kekurangan air akan mengalami keguguran bunga betina yang lebih tinggi serta mengalami gagal tandan atau kerusakan tandan menjadi buah akan meningkat. Aplikasi limbah cair ke lahan dapat meningkatkan persentase bunga betina sehingga perolehan jumlah janjang (janjang/ha) lebih tinggi dibandingkan lahan kontrol.
Dampak Aplikasi Limbah Cair terhadap Kualitas Air. Pemantauan tehadap kualitas air tanah bertujuan untuk mengetahui ada tidaknya dampak pengaruh aplikasi limbah cair terhadap kualitas air tanah, serta mencegah penurunan kualitas dan penggunaan air yang dapat mengganggu dan membahayakan kesehatan. Pemantauan kualitas air yang dilakukan PT AIP untuk menganalisa dampak aplikasi limbah cair yaitu dengan mengambil sampel air dari sumur pantau I, II, dan III yang berada di lahan aplikasi limbah cair, sumur penduduk, dan air sungai (hulu dan hilir).

Kualitas Air Tanah Dangkal (Sumur). Analisis kualitas air tanah dilakukan pada sumur pantau yang terdapat di 3 blok aplikasi limbah yaitu Blok F27 (SP 1), Blok F28 (SP II), dan Blok F29 (SPIII) sedangkan sumur penduduk terdapat di perumahan karyawan divisi II TSE (blok H016). Hasil analisis yang diperoleh kemudian dibandingkan dengan baku mutu Peraturan Menteri Kesehatan No. 416 Tahun 1990 (PERMEN-416/MENKES/PER/IX/1990).

Kualitas Air Sungai Hulu dan Hilir (Air Permukaan). Analisis untuk penilaian kualitas air sungai hulu dan hilir dilakukan terhadap air sungai Pingai hulu dan hilir yag kemudian hasilnya dibandingkan dengan baku mutu air kelas I, II, II, dan IV Peraturan Pemerintah Republik Indonesia No. 82 Tahun 2001 (PP No. 82 Tahun 2001). Hasil pemeriksaan kualitas air sungai hulu dan hilir disajikan pada Tabel 9.

Sampel air yang diambil dari hulu sungai berjarak $2 \mathrm{~km}$ dari pabrik sedangkan sampel air dari hilir sungai berjarak $1 \mathrm{~km}$ dari pabrik. Berdasarkan hasil analisis laboratorium yang disajikan pada Tabel 9, air sungai Pingai Hulu semua parameter memenuhi baku mutu kadar maksimum kecuali nilai BOD melebihi baku mutu kelas I dan II sedangkan $\mathrm{pH}$ kurang dari baku mutu kelas I, II, III dan IV yang dipersyaratkan dalam PP No. 82 tahun 2001. Air sungai Pingai Hilir semua parameter memenuhi baku mutu kecuali nilai BOD melebihi baku mutu kelas I dan II, sedangkan $\mathrm{pH}$ kurang dari baku mutu kelas I, II, III dan IV yang dipersyaratkan dalam PP No. 82 Tahun 2001.

Air sungai hilir mempuyai nilai $\mathrm{pH}$ yang rendah dikarenakan air yang berasal dari hulu sungai sudah mempunyai nilai $\mathrm{pH}$ yang rendah. Apabila dilihat dari nilai $\mathrm{pH}$ pada air sungai hulu dan hilir yang kurang dari baku mutu yang telah ditentukan maka air sungai tersebut tidak cocok digunakan sesuai dengan golongan air kelas I, II, III dan IV PP No. 82 Tahun 2001. Apabila dilihat dari nilai BOD, COD dan parameter pencemaran 
lainnya, air sungai hulu dan hilir sudah memenuhi baku mutu (kadar maksimum) yang dipersyaratkan sesuai golongan air kelas III dan IV sehingga aplikasi limbah cair sudah aman dilakukan serta tidak berdampak negatif bagi air sungai.

Air sungai hilir mempuyai nilai $\mathrm{pH}$ yang rendah dikarenakan air yang berasal dari hulu sungai sudah mempunyai nilai $\mathrm{pH}$ yang rendah. Apabila dilihat dari nilai $\mathrm{pH}$ pada air sungai hulu dan hilir yang kurang dari baku mutu yang telah ditentukan maka air sungai tersebut tidak cocok digunakan sesuai dengan golongan air kelas I, II, III dan IV PP No. 82 Tahun 2001. Apabila dilihat dari nilai BOD, COD dan parameter pencemaran lainnya, air sungai hulu dan hilir sudah memenuhi baku mutu (kadar maksimum) yang dipersyaratkan sesuai golongan air kelas III dan IV sehingga aplikasi limbah cair sudah aman dilakukan serta tidak berdampak negatif bagi air sungai.

Pengelolaan dan pemanfaatan limbah cair dengan cara diaplikasikan ke lahan yang dilakukan perusahaan tidak berdampak negatif bagi air sungai karena tidak ada limbah yang dibuang secara langsung ke sungai. Hal tersebut menunjukkan bahwa perusahaan sudah melakukan pengawasan yang baik terhadap kemungkinan rembesan dan limpahan air limbah baik dari kolam limbah di stasiun IPAL maupun dari dalam flat bed di lahan aplikasi.

\section{KESIMPULAN}

Kegiatan magang sudah meningkatkan pengetahuan dan pengalaman penulis dalam melakukan proses kerja secara nyata di lapangan khusunya mengenai teknik budidaya kelapa sawit serta menambah wawasan tentang aspek manajerial dalam pengelolaan kebun kelapa sawit.

Produk sampingan (by product) yang dihasilkan proses pengolahan TBS dimanfaatkan untuk pupuk organik yang diaplikasikan ke lahan. Jumlah JJK yang diterima TSE sebanyak 17 667.42 ton/tahun dan luas lahan yang diaplikasikan JJK pada tahun 2011/2012 yaitu 461.3 ha (sekitar $15.82 \%$ dari luas total TSE). Aplikasi JJK di lahan tidak memberikan pengaruh secara nyata terhadap kandungan unsur hara dalam daun dan secara keseluruhan aplikasi JJK belum dapat meningkatkan perolehan produktivitas secara konsisten. Aplikasi JJK juga belum dapat menggantikan penggunaan pupuk anorganik tetapi hanya sebatas penambah unsur hara dan pembenah tanah saja.

Aplikasi limbah cair ke lahan berdampak positif terhadap peningkatan kandungan unsur hara $\mathrm{N}$ dan $\mathrm{P}$ dalam daun serta memberikan dampak positif bagi perolehan produksi tanaman kelapa sawit terutama terhadap produktivitas (ton/ha). Limbah cair yang diaplikasikan ke lahan menyebabkan air sumur penduduk yang ada di sekitar lahan aplikasi dan air permukaan (sungai) tidak dapat digunakan sebagai air minum karena tidak memenuhi baku mutu standar yang ditentukan yaitu nilai $\mathrm{pH}$ yang rendah. Apabila dilihat dari parameter pencemar limbah secara keseluruhan aplikasi limbah cair aman dilakukan karena tidak berdampak negatif bagi air sumur maupun air sungai, selain itu perusahaan tidak membuang limbah ke sungai.

\section{DAFTAR PUSTAKA}

Budianta, D. 2005. Potensi limbah cair pabrik kelapa sawit sebagai sumber hara untuk tanaman perkebunan. Jurnal Dinamika Pertanian 20(3):273-282.

Badan Pusat Statistik. 2011. Luas Tanaman Perkebunan Besar Menurut Jenis Tanaman, Indonesia, $1995 \quad-\quad 2009$. http://www.bps.go.id. [2 Mei 2011].

Darmosarkoro, W., dan S. Rahutomo. 2003. Tandan kosong kelapa sawit sebagai bahan pembenah tanah, p. 167-179. Dalam W. Darmasarkoro, E.S. Sutarta dan Winarna (Eds.). Lahan dan Pemupukan Kelapa Sawit. Pusat Penelitian Kelapa Sawit. Medan.

Darmosarkoro, W., I. Y. Harahap, E. Syamsudin, H. H. Siregar, dan E. S. Sutarta. 2005. Antisipasi dan Penanggulangan Pengaruh Kekeringan pada Kelapa Sawit. Pusat Penelitian Kelapa Sawit. Medan.

Direktorat Jenderal Perkebunan. 2011. 2011. Volume dan nilai ekspor, impor Indonesia. http://ditjenbun.deptan.go.id. [2 Mei 2011].

Lubis, A. U. 1992. Kelapa Sawit (Elaeis guineensis Jacq.) di Indonesia. Pusat 
Bul. Agrohorti 3 (2): 202-212 (2015)

Penelitian Perkebunan Marihat-Bandar Kuala. Sumatera Utara. 435 hal.

Minamas Research Centre, Minamas Plantation. 2009. Hasil Analisa Daun. Minamas Research Centre, Minamas Plantation. Teluk Siak.
Unit Pelaksana Teknis Pengujian. 2011. Laporan Hasil Pemeriksaan Limbah Cair PT Aneka Intipersada. Dinas Pekerjaan Umum Provinsi Riau.

Walpole, R. E. 1993. Pengantar Statistika. Edisi ke-3. Penerbit PT Gramedia Pustaka Utama, Jakarta. 